\title{
Direct and indirect effects of solar variations on stratospheric ozone and temperature
}

\author{
SHANG Lin ${ }^{1}$, TIAN WenShou ${ }^{1 *}$, DHOMSE Sandip ${ }^{2}$, CHIPPERFIELD Martyn $\mathrm{P}^{2}$, LIU $\mathrm{Yi}^{3} \&$ \\ WANG WuKe ${ }^{1}$ \\ ${ }^{1}$ Key Laboratory of Semi-Arid Climate Change, Ministry of Education, College of Atmospheric Sciences, Lanzhou University, \\ Lanzhou 730000, China; \\ ${ }^{2}$ Institute for Climate and Atmospheric Science, School of Earth and Environment, University of Leeds LS1 3HE, UK; \\ ${ }^{3}$ Key Laboratory of Middle Atmosphere and Global Environment Observation, Institute of Atmospheric Physics, Chinese Academy of Sciences, \\ Beijing 100029, China
}

Received January 16, 2013; accepted March 6, 2013; published online May 3, 2013

\begin{abstract}
We have used a fully coupled chemistry-climate model (WACCM) to investigate the relative importance of the direct and indirect effects of 11a solar variations on stratospheric temperature and ozone. Although the model does not contain a quasi-biennial oscillation (QBO) and uses fixed sea surface temperature (SST), it is able to produce a second maximum solar response in tropical lower stratospheric (TLS) temperature and ozone of approximately $0.5 \mathrm{~K}$ and $3 \%$, respectively. In the TLS, the solar spectral variations in the chemistry scheme play a more important role than solar spectral variations in the radiation scheme in generating temperature and ozone responses. The chemistry effect of solar variations causes significant changes in the Brewer-Dobson (BD) circulation resulting in ozone anomalies in the TLS. The model simulations also show a negative feedback in the upper stratosphere between the temperature and ozone responses. A wavelet analysis of the modeled ozone and temperature time series reveals that the maximum solar responses in ozone and temperature caused by both chemical and radiative effects occur at different altitudes in the upper stratosphere. The analysis also confirms that both the direct radiative and indirect ozone feedback effects are important in generating a solar response in the upper stratospheric temperatures, although the solar spectral variations in the chemistry scheme give the largest solar cycle power in the upper stratospheric temperature.
\end{abstract}

solar cycle, stratospheric ozone, stratospheric temperature, chemistry, radiation

Citation: $\quad$ Shang L, Tian W S, Dhomse S, et al. Direct and indirect effects of solar variations on stratospheric ozone and temperature. Chin Sci Bull, 2013, 58: 3840-3846, doi: 10.1007/s11434-013-5822-2

It is well known that solar variations are an important source of low frequency atmospheric variability and its signature exists not only in the stratosphere and ionosphere but also in the troposphere [1-4]. Although the total solar irradiance (TSI) varies by only $\sim 0.1 \%$ during a solar cycle [5], nearly $6 \%$ changes are observed in the ultraviolet (UV) region of the solar spectrum [6], which are enough to change the ozone and temperature in the stratosphere and influence the troposphere [7,8]. Using various satellite data sets, Soukharev and Hood [9] showed a double-peak-structured solar

*Corresponding author (email: wstian@1zu.edu.cn) response in stratospheric ozone (minimum response in the mid-stratosphere, see also Randel and Wu [10]). They argued that the upper stratospheric solar response is of photochemical origin whereas the lower stratospheric response is controlled by dynamics. Along with other studies, Randel et al. [11] and Frame and Gray [12] reported double-peak solar responses in stratospheric temperatures. However, Schmidt et al. [13] pointed out that the temperature response up to the mesopause is strongly influenced by changes in dynamics. Using series of simulations of coupled chemistryclimate models, Austin et al. [14] and Schmidt et al. [13] found that during the 11-year solar-cycle stratospheric ozone 
and temperatures can vary up by to $2.5 \%$ and $0.8 \mathrm{~K}$, respectively. They argued that the QBO is not necessary to simulate the solar response in the TLS and SSTs may be involved in the ozone solar responses. However, it is still unclear from these studies how and to what an extent SSTs and dynamical transport are aliased with solar responses in the TLS. On the other hand, Matthes et al. [15] showed the necessity of the QBO to simulate the TLS solar response through changes in stratospheric circulation. Kodera and Kuroda [16] suggested that upper stratospheric ozone changes alter the planetary wave propagation and they argued that there is less wave forcing during solar maxima and hence less ozone is transported from tropics to mid-high latitudes [17]. So, despite the recognized importance of climatic effects of solar variability, there are still many uncertainties in the detected solar responses in ozone, temperature and various other climate factors [3, and references therein]. And the largest source of uncertainty comes from the dynamical coupling between solar-induced changes and the atmospheric chemistry.

During the last few decades, various modeling studies have improved our understanding of solar-cycle-related variability on the Earth's climate [7,18]. The common method to simulate the solar cycle is to include either changes in total solar irradiance (TSI) or changes in UV radiation to account for ozone changes through photochemistry. Recently developed chemistry-climate models (CCMs) can incorporate ozone feedbacks to solar variation [19] and some of these models can simulate the solar response in ozone and temperatures reasonably well [14]. Merkel et al. [20] found that the ozone response is caused by the photochemistry related to the UV variability and if the UV has a small magnitude of the variability then the ozone will has a small response. However, in these previous CCM studies, the relative contributions of direct solar heating changes and ozone photochemistry changes associated with solar variations in forcing atmospheric responses are unclear [21].

In this study we perform a series of CCM simulations to investigate atmospheric responses to the solar cycle. The solar variations are incorporated separately in the radiation scheme and chemistry scheme (resolved changes in solar spectrum), and the magnitude of the both changes is different in different wave band. The QBO is not included in the simulations to exclude the interaction between solar variations and the QBO. Our main focus is to quantify the effect of ozone feedbacks to 11-year solar variations and we attempt to distinguish the relative importance of spectral variations of the radiation scheme and spectral variations of the chemistry scheme in generating solar responses in stratospheric temperatures and ozone. The details of the model and numerical experiments are described in Section 2. The ozone and temperature feedbacks to solar cycle are discussed in Section 3. A summary and conclusions are given in Section 4.

\section{Model and numerical experiments}

We have used the Whole Atmosphere Community Climate Model (WACCM) which is a global climate model with 66 vertical levels extending from the surface to $4.5 \times 10^{-6} \mathrm{hPa}$ $(\sim 160 \mathrm{~km})$. WACCM incorporates a detailed chemistry module for the middle and upper atmosphere with a good performance in various aspects [22,23]. We conducted three simulations at a horizontal resolution of $4^{\circ} \times 5^{\circ}$ with interactive chemistry. In control run (R0) the solar cycle changes are incorporated in both the radiation and the chemistry schemes. In run R1, the solar spectral variations are included only in the model's radiation scheme while in run $\mathrm{R} 2$, the solar spectral variations are included only in the model's chemistry scheme. The TSI time series used in these simulations is from Lean et al. [24] and is shown together with F10.7 cm solar flux (another proxy for solar variability) in Figure 1(a). The three simulations were run for 50 years from 1950 to 2000 with the first 15 years excluded to account for the model spin-up and including 3 complete solar cycles. The sea surface temperatures (SSTs) and sea ice fields used in the model are 12-month climatologies derived from Rayner et al. [25]. The concentrations of ozone-depleting substances (ODSs) and greenhouse gases (GHGs) are time varying and follow the IPCC scenario A1B [26].

Figure 1(b) shows the simulated tropical total column ozone (TCO) and $100 \mathrm{hPa}$ temperature anomalies from control run R0 as well as the corresponding TCO anomalies derived from TOMS/SBUV merged data and ground-based measurements from World Ozone and Ultraviolet Radiation Data Centre. Overall, the simulated TCO anomalies capture long-term ozone decrease and slight increase in recent years (due to decreased halogen loading). Modeled TCO variations in the tropics are in phase with the solar variations, although the amplitude of the simulated TCO anomalies is smaller than the observed in the early 1990s. SPARC [23] stated that none of the 18 participating CCMs in the Chemistry-Climate Model Validation Activity (CCMVal-2) could simulate the changes of the stratospheric ozone correctly after large volcanic eruptions. So underestimation of the TCO in the early 1990s in Figure 1(b) is possibly due to the effects of the Mt. Pinatubo eruption and the volcanic aerosol are not well simulated in the model [23]. Figure 1(b) also indicates that the simulated tropical temperature anomalies at $100 \mathrm{hPa}$ are well in phase with 11 a solar cycle variations.

\section{Ozone and temperature feedbacks to solar variations}

Figure 2 shows latitude-height cross-sections of annual mean temperature and ozone differences in solar maximum years relative to solar minimum years from the three simulations. Control run R0 (solar variations in both radiation and chemistry schemes) shows a significant positive temperature 

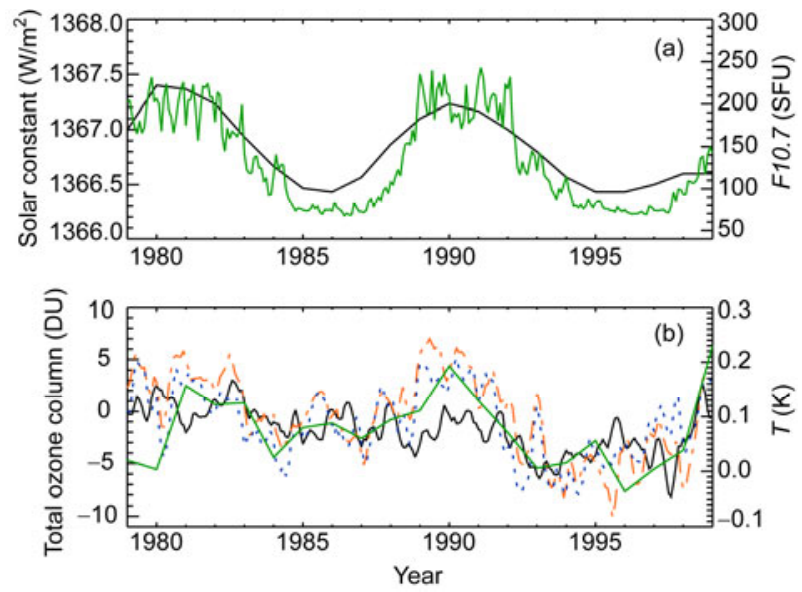

Figure 1 (a) The time series of the solar constant (black line) and F10.7 flux (green line) from 1979-1999 used in the model simulations. (b) The model total column ozone anomalies (DU, black line), the $100 \mathrm{hPa}$ temperature anomalies (K, green line) and corresponding anomalies from satellite (red) and ground-based (blue) total column ozone measurements.

response $(\sim 0.5 \mathrm{~K})$ in the TLS, which is in agreement with Frame and Gray [12]. A positive ozone response in the TLS (Figure 2(b)) are also clearly visible. However, the model simulates very little ozone response in the upper strato- sphere; the simulated solar response in ozone is similar to that of Schmidt et al. [13]. Note that the upper stratosphere solar responses of ozone and temperature have been widely debated in the literature. Using ozone profile data from satellite instruments (SAGE, SBUV, HALOE), some studies $[9,10]$ have shown that a significant positive solar response exists in the tropical upper stratosphere. The modeling study by Egorova et al. [27] showed that the ozone response is positive throughout the tropical stratosphere but turns negative in the mesosphere. However, using HALOE satellite data from 1992 to 2005, Remsberg [28] found no significant solar response in tropical upper stratospheric ozone.

Another interesting feature in Figure 2 is that the modeled temperature response is less than that derived by Frame and Gray [12] from ERA-40 data, which may be caused by the fixed SST [29]. However, it is also important to remember that Dhomse et al. [30] and Randel et al. [11] noted inhomogeneities of temperature in the ERA-40 data which may introduce biases in detected temperature responses. On the other hand, a positive solar response in both temperature and ozone in the upper stratosphere may not be unrealistic. Dhomse et al. [31] showed that a $1 \mathrm{~K}$ temperature increase in the upper stratosphere can lead to a $1 \%$ decrease in ozone in that region. In our simulations, we also find that the
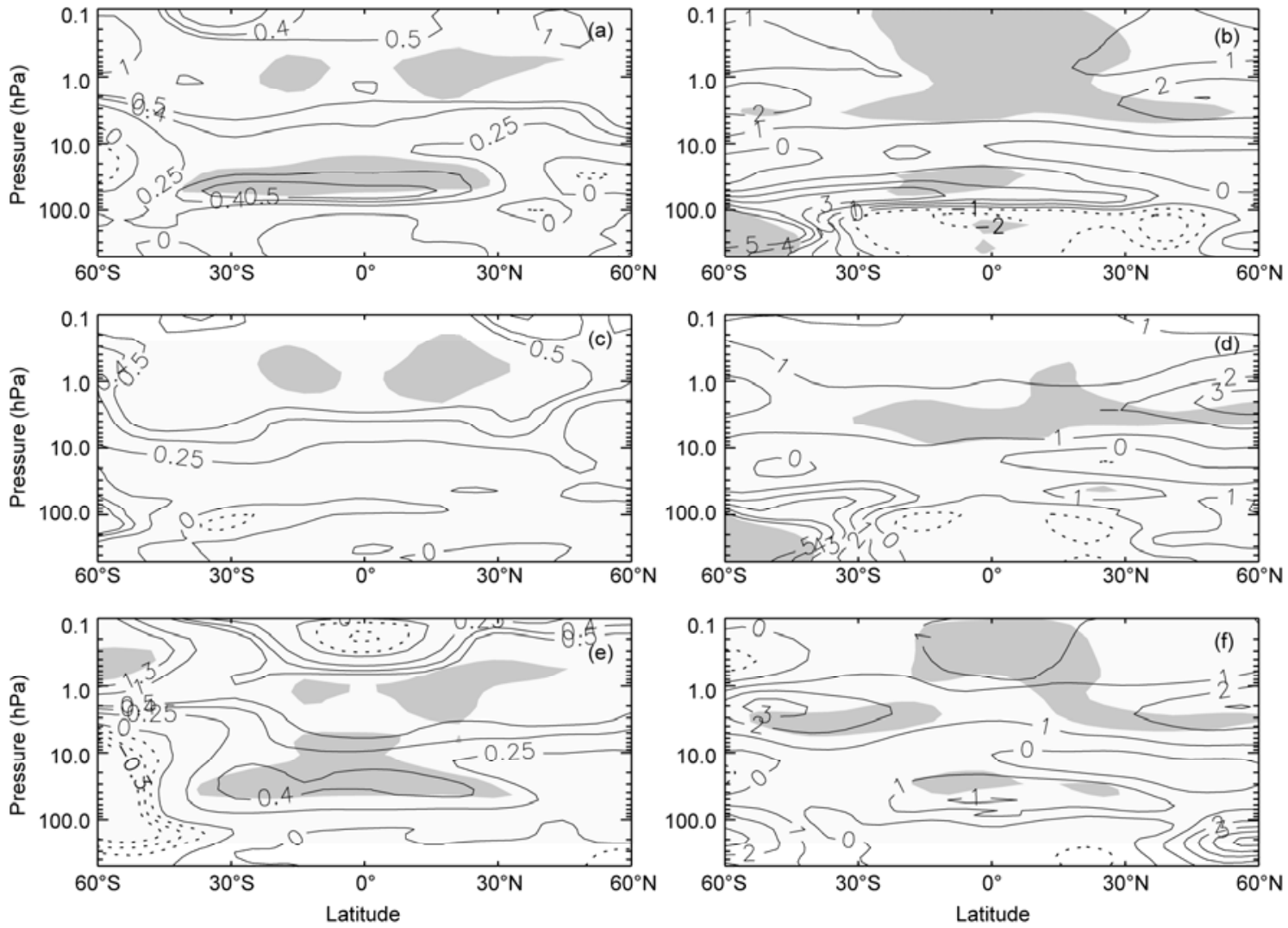

Figure 2 Latitude-height cross-sections of (a), (c), (e) annual mean temperature (K) and (b), (d), (f) ozone differences in \% of solar maximum years relative to solar minimum years in (a), (b) control run R0, (c), (d) run R1, and (e), (f) run R2. The positive and negative contours are represented by solid and dotted lines, respectively. The contour interval for temperature is unequal and it is $1 \%$ for ozone. Shaded regions show where the differences are statistically significant at the $90 \%$ confidence level using Student's $t$-test. 
temperature and ozone anomalies are negatively correlated in the upper stratosphere above $1 \mathrm{hPa}$ when only the data of northern winter months (December to February) are composited (not shown). Note that previous studies have shown that the effect of the solar forcing is most significant during northern hemisphere winter [32-34].

The vertical structure of our modeled ozone response to solar variations in the tropical lower and middle stratosphere is overall similar to those detected in earlier studies using SBUV, SAGE, HALOE satellite data and numerical models $[9,10,35,36]$. The solar response in the TLS temperature (Figure 2(a)) is in accordance with the ozone response with a $0.5 \mathrm{~K}$ temperature anomaly corresponding to a $3 \%$ ozone changes, and consistent with the result in the previous study that positive responses of the temperature are accompanied by positive ozone changes [37]. Note that the tropics to mid-latitude "double-lobed" structured ozone response reported in previous literature [35] is not captured by the model possibly because that the QBO variations are not included in our simulations.

When solar spectral variations are only included in the model's radiation scheme (run R1), the structures of temperature and ozone responses in the tropical stratosphere (Figure 2(c), (d)) are quite different to that in the control run $\mathrm{R} 0$. In the TLS, the temperature response becomes weaker, changing from $0.5 \mathrm{~K}$ in control run $\mathrm{R} 0$ to $0.2 \mathrm{~K}$. The centers of the temperature and the ozone maximum anomalies disappear. This clearly shows that the TLS ozone and temperature responses are not sensitive to direct radiative effect of the spectral variations in the radiation scheme. If solar spectral variations are included only in the chemistry scheme (run R2), the ozone and temperature responses are nearly the same as the control run R0 (Figure 2(e), (f)). However, in the TLS, the temperature response becomes slightly weaker. Particularly noticeable is that the temperature response changes from positive to negative in the upper stratosphere near $0.1 \mathrm{hPa}$. It is apparent that solar spectral variations in the chemistry scheme generate the maximum response of the temperature and ozone in the TLS and the positive temperature responses are accompanied with positive ozone anomalies, consistent with the corresponding results in previous studies [18,37]. Without direct radiative heating changes due to the spectral variations in the radiation scheme, the maximums and mid-stratospheric negative ozone response become smaller and statistically insignificant. Another interesting feature in Figure 2 is that in the tropical troposphere, negative ozone anomalies can be noted in all three runs. The composited $\mathrm{OH}$ differences in solar maximum years relative to solar minimum years from the three simulations indicate that more $\mathrm{OH}$ is generated in the troposphere during solar maximum years (not shown).

Figure 2 shows that positive ozone anomalies are accompanied by positive temperature responses in the TLS. A questions arises here as whether the ozone changes in the TLS associated with radiatively forced temperature changes via temperature dependence of photolysis rates. Austin et al. [14] concluded from their analysis that the tropical upper stratospheric ozone anomalies are radiatively driven while those in the TLS are driven indirectly by changes in advection (tropical ascent driven by extratropical wave forcing). Gray et al. [38] similarly suggested that the TLS ozone response is due to dynamical redistribution. However, it is unclear whether it is the direct radiative effect or the chemical effect of solar variations that induces changes the BD circulation and hence resulting in ozone change in the TSL. To clarify this issue, Figure 3 shows the E-P flux and BD circulation differences between solar maximum years and solar minimum years in the three experiments. It is apparent that solar variations cause anomalous downward propagation of waves in the mid-latitude stratosphere (Figure 3(a)) and anomalous downwelling in the tropics (Figure 3(b)). The anomalous downweling in the tropics will cause ozone increases in the TLS due to less upward transport of ozone poor air from the upper troposphere into the TLS and the result here is consistent with that in Kodera and Kuroda [16]. When solar variations are only included in the model's radiation scheme, the anomalous upward propagation of waves can be seen in the mid-latitude stratosphere (Figure 3(c)) while in the tropics there is anomalous upwelling (Figure $3(d)$ ), suggesting that the direct radiative effect of solar variations can not cause ozone increases in the TLS. When solar variations are only included in the model's chemistry scheme, the changes in the EP flux and tropical upwelling are similar to those in control run R0 (Figure 3(e), (f)). Figure 3 clearly shows that it is the chemistry effect of solar variations that causes the ozone anomalies in the TSL via modulating the BD circulation.

Figure 4 further compares the E-P flux and BD circulation in solar maximum years and solar minimum years separately between runs $\mathrm{R} 0$ and $\mathrm{R} 1$. Relative to run $\mathrm{R} 1$ in which solar variations are only included in the model's radiation scheme, the upward propagation of wave activities in the mid and high latitude stratosphere and the tropical upwelling are significant depressed in control run R0 in solar maximum years (Figure 4(a), (b)), while in solar minimum years reversed results can be clearly seen. The results here further conform that the chemical effect of solar variations causes ozone and temperature anomalies in the stratosphere and then results in changes in the BD circulation which are mainly responsible for the TLS maximum of both ozone and temperature anomalies associated with solar variations.

To further investigate the robustness of the estimated solar response due to spectral variations in the radiation scheme and spectral variations in the chemistry scheme, we performed a wavelet analysis on the simulated percentage ozone (subtracted and then divided by the climate mean of original time series) and temperature time series in the tropics averaged between $25^{\circ} \mathrm{N}-25^{\circ} \mathrm{S}$. Figure 5 shows the vertical distributions of scale-averaged mean wavelet power for 1012 a periods for the three runs. From the temperature time 

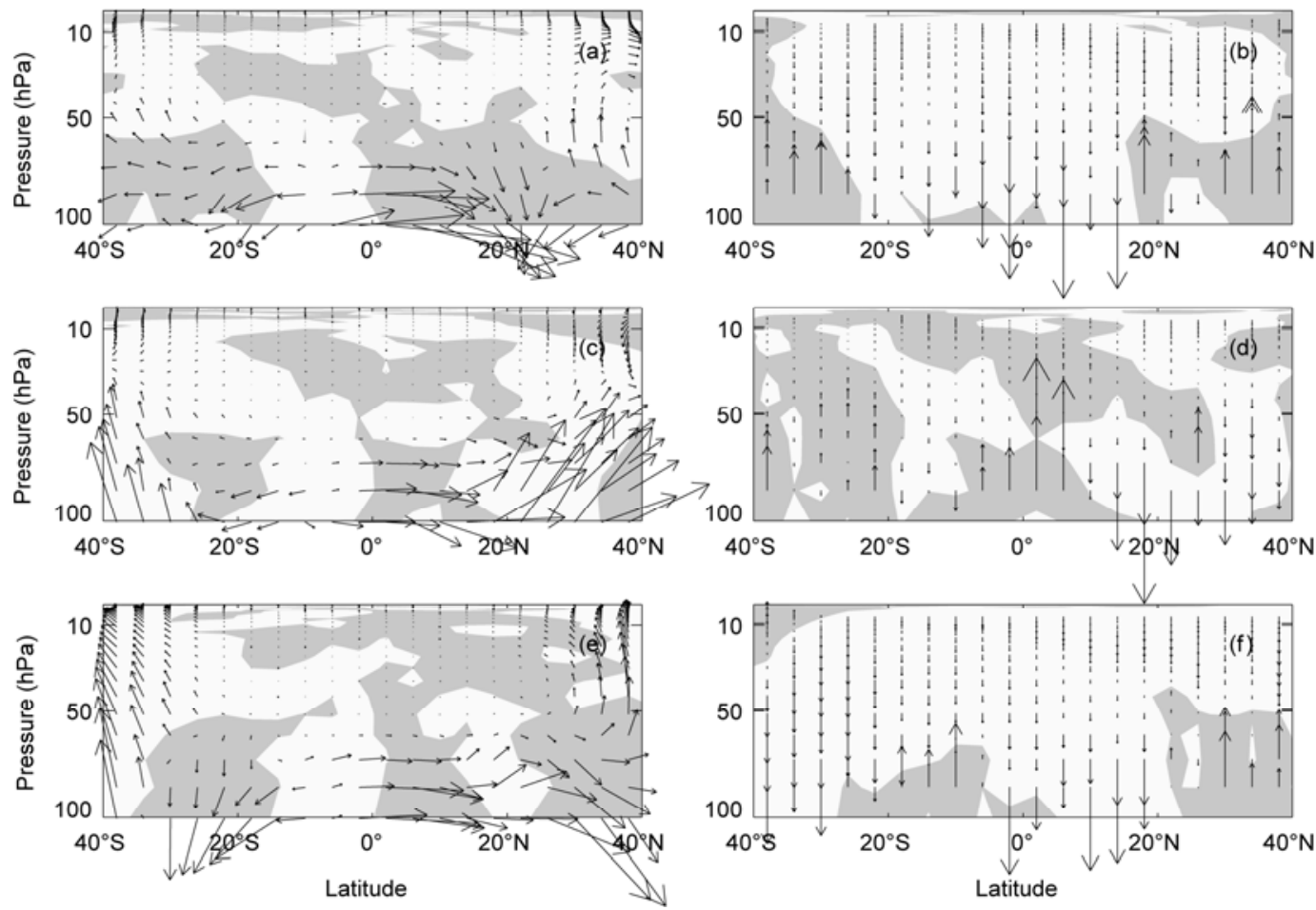

Figure 3 Latitude-height cross-sections of (a), (c), (e) E-P flux and (b), (d), (f) BD circulation differences in solar maximum years relative to solar minimum years in (a), (b) control run R0, (c), (d) run R1, and (e), (f) run R2. The white and shaded regions in (a), (c) and (e) represent the divergence and convergence of the E-P flux, respectively. The white and shaded regions in (b), (d) and (f) represent the downward and upward vertical velocity anomalies, respectively.
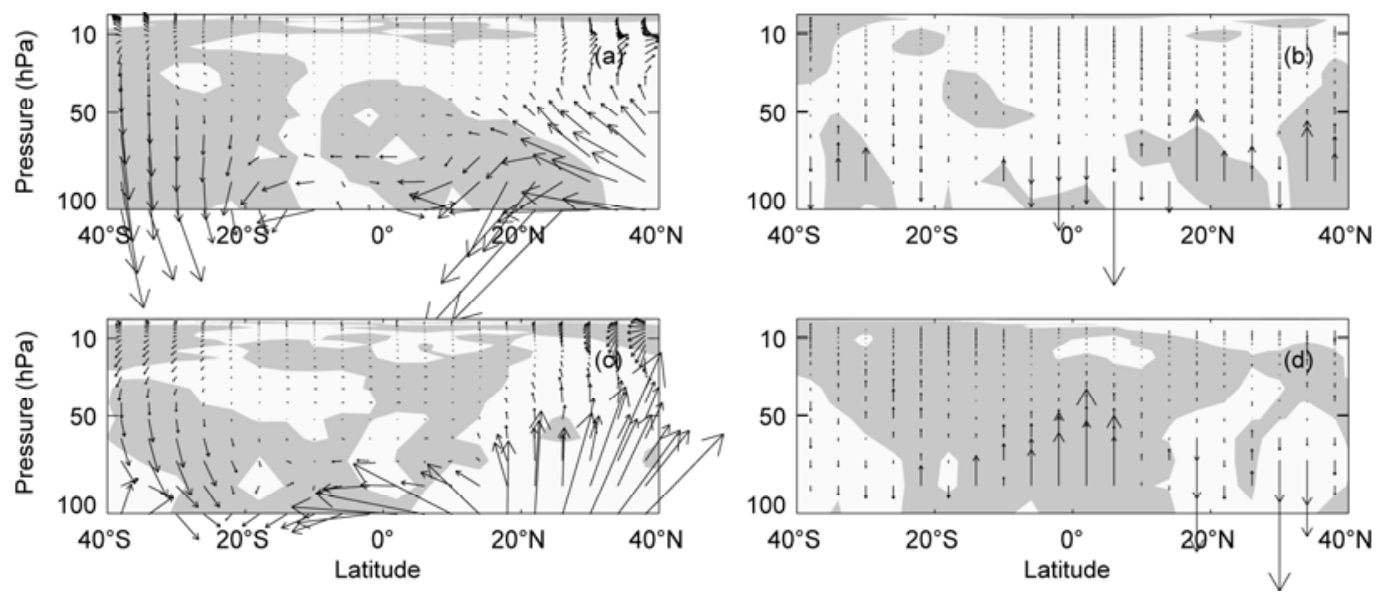

Figure 4 Latitude-height cross-sections of (a), (c) E-P flux and (b), (d) BD circulation differences in R0 relative to R1 in (a), (b) solar maximum years, (c), (d) solar minimum years. The white and shaded regions in (a) and (c) represent the divergence and convergence of the E-P flux, respectively. The white and shaded regions in (b) and (d) represent the downward and upward vertical velocity anomalies, respectively.

series, all three runs show a maximum solar cycle power in the upper stratosphere (between $1-0.1 \mathrm{hPa}$ ) and the secondary solar cycle power maxima in the TLS is also noticeable. However, some key differences between the three runs are evident. In the upper stratosphere, the estimated solar cycle power from control runs R0 is larger than that from the run R1 and smaller than that from the run R2. This highlights the negative feedback between upper stratospheric ozone and temperature that results in a smaller solar response in the upper stratospheric temperature. Solar spectral variations in the chemistry scheme alone (run R2) give the largest solar cycle power in the upper stratospheric temperature. However, radiative heating through spectral variations in the radiation scheme also results in a significant solar cycle power. This implies that both the direct radiative effect and indirect ozone feedback effect of solar variations are important in generating solar response in the upper stratospheric temperatures. In the TLS both radiation and photochemistry 


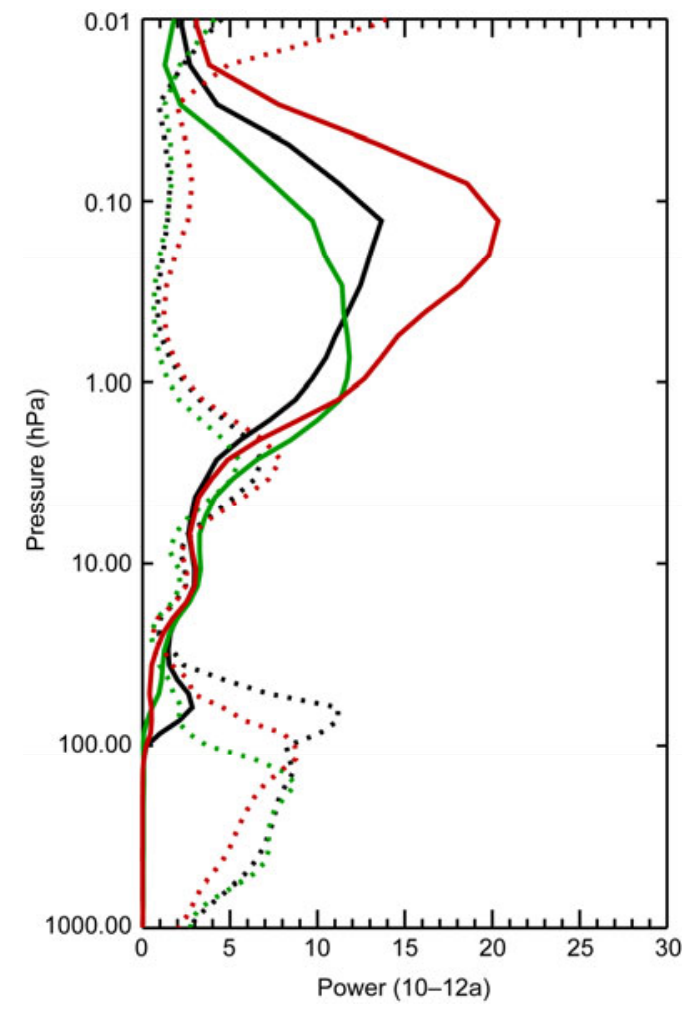

Figure 5 The scale-averaged mean wavelet power for periods from 1012 years in modeled time series of tropical ozone (dashed line) and temperature (solid line) in control run R0 (black line), run R1 (green line), and run R2 (red line).

contribute positively to the temperature response. However, the contribution from run R1 (TSI-induced heating changes) is larger than run R2 (ozone production associated feedbacks).

In the upper stratosphere, similar features are observed in the ozone time series although the largest solar cycle power is observed at lower altitudes (near $5 \mathrm{hPa}$ ) than for temperatures. As expected, changes in ozone production in R2 due to solar spectrum variations in the chemistry scheme give larger power than in R1. The negative feedback between ozone and temperatures is also visible above $1 \mathrm{hPa}$ where ozone time series show very little power. The most interesting feature in ozone time series is the larger power in the TLS than in the upper stratosphere in all the runs. In the stratosphere the contribution of the solar response from spectral changes in the radiation scheme is smaller than that from spectral changes in chemistry scheme, but in the troposphere the spectral variations in the radiation scheme play a more important role. It is worth noting that if wavelet analysis is performed on the original ozone time series rather than on percentage ozone time series, the power in the TLS is rather small while the power in middle stratosphere is rather large. Comparing the power distributions of ozone and temperature, we can see that the maximum solar signals in ozone and temperature are co-located with each other in the TLS, but in the upper stratosphere the maximum solar signal in temperature occurs at a much higher altitude than that in ozone. This suggests that in the upper stratosphere ozone-temperature feedbacks are not the main factor driving solar responses in them.

\section{Summary and conclusions}

Our CCM simulations show that a maximum response in temperature and ozone in the lower stratosphere can be simulated by the model even without the interactions between solar forcing and QBO or the interactions between the atmosphere and global ocean temperatures. The maximum temperature and ozone responses in the upper stratosphere are relatively weak and statistically insignificant in the model. This result may suggest that there exist some offsetting effects between the temperature and ozone responses in the upper stratosphere and this is also confirmed by the wavelet analysis of modeled temperature and ozone time series. However, uncertainties in the solar responses in the upper stratosphere detected from both observations and model simulations in previous studies prevent us from drawing a robust conclusion in this region and longer term observations are needed to clarify those uncertainties.

The simulated temperature and ozone responses due to the combined effects of solar heating changes and ozone feedbacks to solar spectral changes in the chemistry scheme in the lower stratosphere were approximately $0.5 \mathrm{~K}$ and $3 \%$, respectively. This temperature difference is slightly lower than that simulated by Gray et al. [38] who used a fixed dynamical heating model without interactive chemistry and also lower than in ERA-40 data. Our simulations suggest that solar spectral changes in chemistry scheme play a more important role than the spectral changes in radiation scheme in generating temperature responses in the lower stratosphere. The ozone feedbacks to solar spectral variations in chemistry scheme can generate maximum temperature responses of 0.4 and $0.8 \mathrm{~K}$ in the lower stratosphere and upper stratosphere, respectively. The analysis also reveals that it is the chemical effect of solar variations that gives rise to ozone and temperature anomalies in the stratosphere and then results in changes in the BD circulation, while the $\mathrm{BD}$ circulations changes are mainly responsible for the TLS maximum of both ozone and temperature anomalies associated with solar variations.

Consistent with the solar signals detected from the composite analysis, the wavelet analysis of simulated temperature and ozone time series shows a maximum solar cycle power in the upper stratosphere and a secondary solar cycle power maximum in the TLS. An interesting feature detected by the wavelet analysis is a negative feedback between upper stratospheric ozone and temperature responses. Also noticeable is that the maximum solar signal in ozone and temperature occur at different altitudes in the upper stratosphere; this result suggests that the temperature response in 
the upper stratosphere is not solely a direct response of ozone changes. Finally, although the solar spectral variations in the chemistry scheme gives the largest solar cycle power in the upper stratospheric temperature, both the direct radiative and indirect ozone feedback effect are important in generating solar response in the upper stratospheric temperatures.

This work was supported by the National Basic Research Program of China (2010CB428604) and the National Natural Science Foundation of China (41175042 and 41225018). We acknowledge computing resources and time on the Supercomputing Center of Cold and Arid Region Environment and Engineering Research Institute of Chinese Academy of Sciences.

1 Labitzke K, van Loon H. Associations between the 11-year solar cycle, the QBO and the atmosphere. Part I: The troposphere and stratosphere in the Northern Hemisphere winter. J Atmos Terr Phys, 1988, 50: 197-206

2 Kodera K. Solar cycle modulation of the North Atlantic Oscillation: Implication in the spatial structure of the NAO. Geophys Res Lett, 2002, 29: 1218

3 Gray L J, Geller M, Haigh J D, et al. Solar influences on climate. Rev Geophys, 2010, 48: RG4001

4 Liu L B, Wan W X, Chen Y D, et al. Solar activity effects of the ionosphere: A brief review. Chin Sci Bull, 2011, 56: 1202-1211

5 Lean J. Variations in the Sun's radiative output. Rev Geophys, 1991, 29: 505-536

6 Lean L, Rottman J, Kyle G J, et al. Detection and parameterization of variations in solar mid- and near-ultraviolet radiation $(200-400 \mathrm{~nm})$. J Geophys Res, 1997, 102: 29939-29956

7 Haigh J D. Climate variability and the influence of the sun. Science, 2001, 294: 2109-2111

8 Labitzke $\mathrm{K}$. The global signal of the 11-year sunspot cycle in the atmosphere: When do we need the QBO? Meteorol Z, 2003, 12: 209-216

9 Soukharev B E, Hood L L. Solar cycle variation of stratospheric ozone: Multiple regression analysis of long-term satellite data sets and comparisons with models. J Geophys Res, 2006, 111: D20314

10 Randel W J, Wu F. A stratospheric ozone profile data set for 19792005: Variability, trends, and comparisons with column ozone data. J Geophys Res, 2007, 112: D06313

11 Randel W J, Shine K P, Austin J, et al. An update of observed stratospheric temperature trends. J Geophys Res, 2009, 114: D02107

12 Frame T H A, Gray L J. The 11-yr solar cycle in ERA - 40 data: An update to 2008. J Clim, 2010, 23: 2213-2222

13 Schmidt H, Brasseur G P, Giorgetta M A. Solar cycle signal in a general circulation and chemistry model with internally generated quasi-biennial oscillation. J Geophys Res, 2010, 115: D00I14

14 Austin J, Tourpali K, Rozanov E, et al. Coupled chemistry climate model simulations of the solar cycle in ozone and temperature. $\mathrm{J}$ Geophys Res, 2008, 113: D11306

15 Matthes K, Marsh D, Garcia R, et al. Role of the QBO in modulating the influence of the 11 year solar cycle on the atmosphere using constant forcings. J Geophys Res, 2010, 115: D18110

16 Kodera K, Kuroda Y. Dynamical response to the solar cycle. J Geophys Res, 2002, 107: 4749

17 Weber M, Dhomse S, Wittrock F, et al. Dynamical control of NH and SH winter/spring total ozone from GOME observations in 1995-2002.
Geophys Res Lett, 2003, 30: 1583

18 Haigh J. A GCM study of climate change in response to the 11-year solar cycle. Q J R Meteorol Soc, 1999, 125: 871-892

19 Eyring V, Butchart N, Waugh D W, et al. Assessment of temperature, trace species, and ozone in chemistry-Climate model simulations of the recent past. J Geophys Res, 2006, 111: D22308

20 Merkel A W, Harder J W, Marsh D R, et al. The impact of solar spectral irradiance variability on middle atmospheric ozone. Geophys Res Lett, 2011, 38: L13802

21 Lee J N, Shindell D T, Hameed S. The influence of solar forcing on tropical circulation. J Clim, 2009, 22: 5870-5885

22 Garcia R R, Marsh D R, Kinnison D E, et al. Simulation of secular trends in the middle atmosphere, 1950-2003. J Geophys Res, 2007, 112: D09301

23 Eyring V, Shepherd T G, Waugh D W. Stratospheric Processes and Their Role in Climate (SPARC). Report on the Evaluation of Chemistry-Climate Models, SPARC Rep. 4, World Meteorol Organ, Geneva, Switzerland, 2010

24 Lean J, Beer J, Bradley R S. Reconstruction of solar irradiance since 1610: Implications for climate change. Geophys Res Lett, 1995, 22 : 3195-3198

25 Rayner N A, Parker D E, Horton E B, et al. Global analyses of sea surface temperature, sea ice, and night marine air temperature since the late nineteenth century. J Geophys Res, 2003, 108: 4407

26 WMO. Scientific assessment of ozone depletion: 2006. Glob Ozone Res Monit Proj Rep, 2007, 50: 572

27 Egorova T, Rozanov E, Manzini E, et al. Chemical and dynamical response to the 11-year variability of the solar irradiance simulated with a chemistry-climate model. Geophys Res Lett, 2004, 31: L06119

28 Remsberg E. On the observed changes in upper stratospheric and mesospheric temperatures from UARS HALOE. Ann Geophys, 2008, 26: $1287-1297$

29 Marsh D R, Garcia R R, Kinnison D E, et al. Modeling the whole atmosphere response to solar cycle changes in radiative and geomagnetic forcing. J Geophys Res, 2007, 112: D23306

30 Dhomse S, Weber M, Burrows J. The relationship between tropospheric wave forcing and tropical lower stratospheric water vapor. Atmos Chem Phys, 2008, 8: 471-480

31 Dhomse S, Chipperfield M P, Feng W, et al. Solar response in tropical stratospheric ozone: A 3-D chemical transport model study using ERA reanalyses. Atmos Chem Phys, 2011, 11: 12773-12786

32 van Loon H, Meehl G A, Shea D J. Coupled air-sea response to solar forcing in the Pacific region during northern winter. J Geophys Res, 2007, 112: D02108

33 Matthes K, Kuroda Y, Kodera K, et al. Transfer of the solar signal from the stratosphere to the troposphere: Northern winter. J Geophys Res, 2006, 111: D06108

34 Meehl G A, Arblaster J M, Branstator G, et al. A coupled airsea response mechanism to solar forcing in the Pacific region. J Clim, 2008, 21: 2883-2897

35 McCormack J P, Hood L L. Apparent solar cycle variations of upper stratospheric ozone and temperature: Latitude and seasonal dependences. J Geophys Res, 1996, 101: 20933-20944

36 Lee H, Smith A K. Simulation of the combined effects of solar cycle, quasi-biennial oscillation, and volcanic forcing on stratospheric ozone changes in recent decades. J Geophys Res, 2003, 108: 4049

37 Steinbrecht W, Hassler B, Claude H, et al. Global distribution of total ozone and lower stratospheric temperature variations. Atmos Chem Phys, 2003, 3: 3411-3449

38 Gray, Rumbold S T, Shine K P. Stratospheric temperature and radiative forcing response to 11-year solar cycle changes in irradiance and ozone. J Atmos Sci, 2009, 66: 2402-2417

Open Access This article is distributed under the terms of the Creative Commons Attribution License which permits any use, distribution, and reproduction in any medium, provided the original author(s) and source are credited. 